\title{
De Aparelhos Ideológicos de Estado ao Nascimento da Biopolítica, e volta
}

\author{
Lucas Trindade da Silva \\ Universidade Federal do Rio Grande do Norte \\ (iD) https://orcid.org/0000-0003-3390-2046 \\ lucastrindadedasilva@yahoo.com.br \\ Edemilson Paraná \\ Universidade Federal do Ceará \\ (D) https://orcid.org/0000-0003-3487-9677 \\ edemilsonparana@gmail.com \\ Alexandre Marinho Pimenta \\ Secretaria de Estado da Educação do Distrito Federal \\ (D) https://orcid.org/0000-0001-8285-1930 \\ alexmpimenta1@gmail.com
}

\section{Introdução}

É conhecida a admiração e aproximação de Althusser com vários aspectos da reflexão de Foucault, sendo a reciprocidade também verdadeira (RYDER, 2013). E há, como se sabe, uma vasta literatura sobre 
as aproximações e disjunções entre a teoria marxista e a foucaultiana - que conta, inclusive, com contribuições recentes (READ, 2003; BIDET, 2016; NEGRI, 2017; BUTLER, 2017; PALLOTTA, 2019).

Assim como é possível ler a obra de Max Weber como um mais implícito que deliberado diálogo com a obra de Karl Marx, também não seria possível ler a obra de Michel Foucault como um silencioso diálogo crítico com a obra de seu professor e amigo Louis Althusser? Diálogo ainda mais razoável na medida em que ambos são influenciados por uma mesma tradição de abordagem do conhecimento filosófico e científico (a chamada epistemologia francesa de Bachelard e Canguilhem) e pelo estruturalismo como crítica à anterior hegemonia da tríade humanista formada por fenomenologia, existencialismo e marxismo hegeliano?

Buscaremos realizar, aqui, um mapeamento particular deste debate na aposta de que os achados teóricos provenientes do estudo da governamentalidade (desenvolvidos nos cursos Segurança, Território, População e Nascimento da Biopolítica) tanto desenvolvem e superam certos limites da teoria política althusseriana em Aparelhos Ideológicos de Estado, como regridem (“e volta”) em relação a certos aspectos desta teoria quando o intuito é analisar a constituição (político-ideológica) de subjetividades afins às transformações recentes no padrão de reprodução do capital.

\section{Ideologia e seus Aparelhos de Estado}

No início dos anos 1970, por meio de ensaios e de notas de pesquisa publicadas na revista francesa Le Pensée (ALTHUSSER, 1985), o marxista franco-argelino estruturou sua teoria da ideologia, cuja grande novidade estava no conceito de Aparelho Ideológico de Estado 
(AIE). Após consolidar seu nome através das discussões epistemológicas em torno da obra de Marx, Althusser se preocupa em elevar o patamar de cientificidade do marxismo, mais propriamente sua ciência da história, apresentando contribuições à dimensão da "superestrutura”, que compreende temáticas sobre ideologia e Estado. O conjunto dessas reflexões, importante ressaltar, nunca foram "finalizadas”, estando sempre sob a forma de ensaio, anotação, comentário (BALIBAR, 2014).

A seu ver, é sob o ponto de vista da reprodução — “condição última da produção” (ALTHUSSER, 1985, p. 53) — que esse objetivo pode ser alcançado. Em qualquer modo de produção, os elementos que o compõem precisam ser repostos e reproduzidos, não apenas no âmbito das forças produtivas, mas também no sociopolítico, em suas relações (sociais) de produção. Num modo de produção no qual o corpo social é constituído através do antagonismo de classe, seus agentes são dispostos e formados tanto para executar tarefas que lhes são dispostas na divisão "técnica” do trabalho como para reproduzir a exploração e dominação de classe que a pressupõe.

A reprodução de um modo de produção exige uma realidade para além do "econômico", e sobre essa dimensão o marxismo necessita avançar. Aqui, Althusser lança mão de uma figura conhecida no materialismo histórico para representar o todo social: a topologia infra e superestrutura. Não para defender o economicismo ou uma filosofia do sujeito/história, há muito já abandonadas e criticadas pelo autor, mas como salvaguarda para enfocar os tipos de determinações e causalidades constitutivas do capitalismo, quer seja a autonomia apenas relativa das instâncias políticas e ideológicas, com suas eficácias específicas (ALTHUSSER, 1985, p. 60), ou mesmo "a existência de uma 'ação de retorno da superestrutura sobre a base' ”. 
Nesse intuito, qual seja, de ir além da teoria descritiva do Estado, Althusser (1985, p. 65) elenca os elementos até onde o marxismo clássico pôde contribuir. Contribuição esta que se confunde com as suas próprias limitações. Assim, vê-se nos clássicos do marxismo, além do enfoque no Estado como aparelho repressivo (instrumento/máquina de violência organizada de classe), a distinção entre "poder de Estado" e "aparelho de Estado”. O “objetivo da luta de classes” seria a tomada do "poder de Estado" e a orientação do aparelho de Estado “em função de seus objetivos”. Ausenta-se, no entanto, nos clássicos do marxismo, uma segunda distinção fundamental numa teoria propriamente dita (não apenas descritiva) do Estado: a distinção entre o Aparelho Repressivo de Estado (ARE) e os Aparelhos Ideológicos de Estado (AIE).

É evidente, aqui, a aproximação, apesar de não completa (BALIBAR, 2014, p. xv), com a teoria do Estado ampliado de Gramsci, que alarga os espaços da luta de classes para a cultura e instituições privadas, e com o par Coerção/Hegemonia, na medida em que o ARE é definido por funcionar principalmente "através da violência”, sendo a ideologia secundária, enquanto os AIE funcionam principalmente "através da ideologia”, sendo a violência — "bastante atenuada, dissimulada, ou mesmo simbólica” (ALTHUSSER, 1985, p. 70) — secundária.

ARE e AIE não se distinguem, portanto, para Althusser (1985, p. 69), mais uma vez amparado em Gramsci, ${ }^{1}$ nos termos da diferença entre público e privado. O fundamental, como vimos, é a especificidade das suas funções, de como cada um destes conjuntos funciona na reprodução capitalista.

1“O Estado, que é o Estado da classe dominante, não é nem público nem privado, ele é ao contrário a condição de toda distinção entre o público e o privado” (ALTHUSSER, 1985, p. 69). 
A diferença específica, a unidade na diversidade (igrejas, escolas públicas e privadas, família, partidos, sindicatos, imprensa, rádio, televisão, letras, belas artes, esportes etc.) dos AIE é, portanto, a própria ideologia, enquanto ideologia da classe dominante. A proposição é cristalina: "nenhuma classe pode, de forma duradoura, deter o poder do Estado sem exercer ao mesmo tempo sua hegemonia sobre e nos Aparelhos Ideológicos do Estado” (ALTHUSSER, 1985, p. 71).

Mas se os AIE se definem pelo seu funcionamento principalmente através da ideologia, qual é a função da ideologia?

A resposta primeira é categórica: a função da ideologia é assegurar “a reprodução das relações de produção” (ALTHUSSER, 1985, p. 73). Em distinção à autorrepresentação ideológica da burguesia que conferiria dominância ao AIE político, “ou seja, o regime de democracia parlamentar oriundo do sufrágio universal e das lutas partidárias”, Althusser (ALTHUSSER, 1985, p. 77) atribui dominância ao AIE escolar na reprodução das relações de produção das "formações capitalistas maduras”, mais precisamente, “o par Escola-Família substitui o par Igreja-Família” (ALTHUSSER, 1985, p. 78) como AIE dominante na passagem do pré-capitalismo à sociedade burguesa.

Althusser não se contenta em definir os AIE pelo seu funcionamento principalmente através da ideologia, nem em definir a função da ideologia como assegurar a reprodução das relações de produção. Interessa a Althusser dar os primeiros passos numa resposta à pergunta sobre o que é a ideologia, em oferecer os fundamentos para uma teoria da ideologia em geral.

O autor assume como ponto de partida de seu "esboço esquemático de uma teoria da ideologia” (ou de uma teoria da ideologia em geral) a seguinte proposição: a ideologia não tem história.

A proposição de que a ideologia não tem história em Althusser, 
embora não negue que a sua história seja determinada em última instância pela luta de classes, não remete à crítica de Engels e Marx ao idealismo dos jovens hegelianos de esquerda, ampara-se na proposição freudiana de que o "inconsciente é eterno". ${ }^{2}$ Ser eterno no sentido de não ter história é, para Althusser (ALTHUSSER, 1985, p. 85), não só negar uma concepção de ideologia como mera falsa consciência, mas afirmar a "omnipresença... e portanto imutabilidade” da ideologia “em toda a extensão da história”. Ou seja, como sendo um elemento “constitutivo da humanidade” (BIDET, 2014, p. xxvii), independente de suas diversas formas históricas de manifestação.

“A ideologia representa a relação imaginária dos indivíduos com suas condições reais de existência” (ALTHUSSER, 1985, p. 85). Althusser não nega, portanto, inteiramente os elementos elaborados por Marx e Engels ainda sob a influência da crítica feuerbachiana da religião. É em A Ideologia Alemã que se define tal concepção de ideologia como representação da relação imaginária dos indivíduos com suas condições reais de existência. O problema naquele momento, de corte epistemológico do marxismo, está em conceber tal representação como uma completa inversão quimérica em relação às condições reais de existência, ilusão esta elaborada não por um grupo de cínicos manipuladores (tese da inversão mecanicista), mas produto da divisão do trabalho alienante na sociedade capitalista moderna.

Além disso, a dimensão imaginária, “vivida”, passa a ser constituinte da experiência social em si (ou, como veremos, de qualquer sujeito). “[S]ó existe prática através de e sob uma ideologia”, diz Althusser (1985, p. 93) nos AIE. Ou, como já dizia anteriormente: “A ideologia faz, pois, organicamente parte, como tal, de toda uma tota-

\footnotetext{
${ }^{2}$ Em obra anterior, Pour Marx, Althusser (2015) já tinha relacionado a ideologia, em sua acepção marxista, à inconsciência, onde afirma que a ideologia é profundamente inconsciente.
} 
lidade social. [...] A ideologia [...] é uma estrutura essencial à vida histórica das sociedades” (ALTHUSSER, 2005, p. 238-9).

Para Althusser (1985, p. 88-9), portanto, tal representação, que é a ideologia, não pode ser pensada como um resíduo ideacional ilusório, epifenômeno espontâneo da divisão do trabalho. Tal representação, e aí retorna ao começo do ensaio, "existe sempre em um aparelho e em sua prática ou práticas. Esta existência é material”.

É neste momento que Althusser (1985, p. 91) inicia um raciocínio que será crucial para o nosso diálogo com Michel Foucault. Mais uma vez ele tenta levar aos seus limites uma concepção que julga equivocada de ideologia ou, em suas palavras, uma "ideologia da ideologia” que, a despeito dos seus pendores idealistas, não deixa de reconhecer que “apesar de sua deformação imaginária”, “as ‘ideias’ de um sujeito humano existem em seus atos, ou devem existir em seus atos”.

O equívoco desta concepção está em sua inversão da ordem dos fatores: não são as ideias que encarnam nos atos, mas são os atos que produzem as ideias, intelecção perfeitamente intuída no "ajoelhai-vos, orai e acreditareis” (ALTHUSSER, 1985, p. 91) de Pascal. As “ideias” de "um sujeito (tal indivíduo)... são seus atos materiais inseridos em práticas materiais, reguladas por rituais materiais, eles mesmos definidos pelo aparelho ideológico material de onde provêm as ideias do dito sujeito” (ALTHUSSER, 1985, p. 92). A dinâmica segue, portanto, das práticas/rituais materiais dos aparelhos ideológicos aos atos e então às crenças de um sujeito.

Logo depois, Althusser propõe uma relação de constituição recíproca ou de coconstituição entre "ideologia” e "sujeito": “a ideologia existe para sujeitos concretos, e esta destinação da ideologia só é possível pelo sujeito” (ALTHUSSER, 1985, p. 93), ao ponto de afirmar que a definição sujeito ideológico seria uma "formulação tautológica” 


\section{(ALTHUSSER, 1985, p. 94).}

Queremos dizer com isso, mesmo que esta categoria (o sujeito) não apareça assim denominada, que com o surgimento da ideologia burguesa, e sobretudo com o da ideologia jurídica, a categoria de sujeito (que pode aparecer sob outras denominações: como em Platão por exemplo, a alma, Deus etc.) é a categoria constitutiva de toda ideologia, seja qual for a determinação (regional ou de classe) e seja qual for o momento histórico, - uma vez que a ideologia não tem história (ALTHUSSER, 1985, p. 93).

A citação exige que atentemos para os problemas metodológicos e para as contradições performáticas e paradoxos nos quais se enredam tais inconclusas, como nos lembra Balibar (2014), reflexões de Althusser.

O primeiro ponto é evidente para qualquer leitor atento de Marx, mais precisamente, a qualquer um que tenha adentrado o labirinto da famosa Introdução de 1857 aos Grundrisse. Logo no início desse texto, Marx (2011, p. 40) faz uma crítica aos enunciados que buscam definir a "produção em geral” e um sujeito em geral da produção. Em suas robinsonadas, a economia política considera o indivíduo "desprendido dos laços naturais" e "isolado", o indivíduo da sociedade burguesa, que se relaciona com "as diversas formas de conexão social... como simples meios para seus fins privados”, não como um “resultado histórico, mas como ponto de partida da história” (MARX, 2011, p. 40), eternizando ou naturalizando a produção burguesa e o seu homo oeconomicus.

Contra isto, Marx (2011, p. 41) escreve que a "produção em geral”, como “abstração razoável” que “destaca e fixa o elemento comum”, só é possível com a condição de que, "além da unidade - decorrente do fato de que o sujeito, a humanidade, e o objeto, a natureza, são os mesmos -, não seja esquecida a diferença essencial” entre os diferen- 
tes modos históricos de produção.

A questão fundamental é de que a ideia de produção em geral só é possível quando dependente do conhecimento das diversas fases históricas de produção, enquanto abstração dos elementos comuns a tais diferentes formas de produzir. A produção em geral não pode ser concebida como um esquema a partir do qual são deduzidos os modos particulares de produção, mas, pelo contrário, como resultado da abstração do crescente aprofundamento do conhecimento científico sobre a especificidade daqueles modos particulares.

Tais considerações rejeitariam qualquer afirmação do tipo 'a produção não tem história’ ou 'a produção é eterna', proposições destituídas de fecundidade teórico-conceitual. É, no entanto, como vimos, por esse caminho que Althusser articula sua "teoria da ideologia em geral”, propondo, a partir de fonte heterogênea (psicanálise), a ideia de que a ideologia é eterna no sentido de não ter história.

Segundo ponto. Ao enveredar-se no argumento da dupla constituição, constituição recíproca ou coconstituição ideologia-sujeito, Althusser contradiz a sua premissa anterior sobre a dinâmica da ideologia, que iria das práticas materiais dos aparelhos ideológicos aos atos e então às crenças e ideias de um sujeito. Na relação de coconstituição, sintetizada na afirmação de que "só há ideologia pelo sujeito e para o sujeito” (ALTHUSSER, 1985, p. 93), as práticas e rituais materiais dos aparelhos ideológicos não antecedem a ideia, mas, pelo contrário, uma categoria (o sujeito), numa leitura generosa, tanto constitui como é constituída pelas práticas materiais, ou, na radicalização a que tende a letra do próprio Althusser (1985, p. 93), o sujeito aparece como "a categoria constitutiva de toda ideologia".

Se a ideologia é eterna no sentido de não ter história, e se o sujeito constitui e é constituído pela ideologia, é inevitável a conclusão de 
que também o sujeito é eterno e não tem história.

Terceiro ponto, outra contradição performática. Apesar das suas afirmações sobre a eternidade e ahistoricidade da ideologia, Althusser também oferece elementos, como um pêndulo entre finito e infinito, para uma historicização da categoria do sujeito. Isto se dá, primeiramente, quando o autor afirma, como já vimos, “que com o surgimento da ideologia burguesa, e sobretudo com o da ideologia jurídica, a categoria de sujeito (que pode aparecer sob outras denominações: como em Platão por exemplo, a alma, Deus etc.) é a categoria constitutiva de toda ideologia” (ALTHUSSER, 1985, p. 93). Dá-se também quando Althusser utiliza como exemplo por excelência da dupla constituição ideologia-sujeito a ideologia cristã, definida amplamente como fonte da ideia moderna de indivíduo/sujeito.

Para nós, uma falha sublime, por abrir mais uma saída para os problemas insolúveis da concepção de ideologia “em geral”, “eterna”, "sem história”.

Eu sou um sujeito! “é evidente! é exatamente isso! é verdade!” (ALTHUSSER, 1985, p. 95). Esta "evidência de que vocês e eu”, indivíduos concretos, "somos sujeitos”, este é “o efeito ideológico elementar. Este é, aliás, o efeito característico da ideologia — impor (sem parecer fazê-lo, uma vez que se tratam de 'evidências') as evidências como evidências, que não podemos deixar de reconhecer" (ALTHUSSER, 1985, p. 94).

Eis um elemento científico importante e heuristicamente frutífero do conceito althusseriano de ideologia: o "reconhecimento" de si como um "sujeito" (evidência indiscutível, verdade dada, truísmo) é o ápice da ideologia, que opera precisamente através do "desconhecimento”, para os indivíduos concretos, de que todo "sujeito” é produto de uma operação ideológica. 
Tomando as contribuições de Althusser nesse sentido, não haveria qualquer problema na afirmação de que "você e eu já somos sempre sujeitos” (ALTHUSSER, 1985, p. 95). Somos sempre sujeitos no interior de uma forma histórica de interpelação ideológica, o que não necessariamente quer dizer que a ideologia opera sempre, no sentido de eternamente e ahistoricamente, através da constituição de sujeitos/indivíduos.

Infelizmente, em seu ímpeto de uma teoria da ideologia em geral, é precisamente isto que Althusser (ALTHUSSER, 1985, p. 96) persegue: "toda ideologia interpela os indivíduos concretos enquanto sujeitos concretos, através do funcionamento da categoria de sujeito”.

A interpelação — “que pode ser definida como o tipo mais banal de interpelação policial (ou não) cotidiana: ‘ei, você aí” ”3 - é a operação ou funcionamento por excelência da ideologia ao recrutar "sujeitos dentre os indivíduos (ela os recruta a todos)" ou transformar "os indivíduos em sujeitos (ela os transforma a todos)” (ALTHUSSER, 1985, p. 96). Desta vez, afirma-se que a "existência da ideologia e a interpelação dos indivíduos enquanto sujeitos são uma única e mesma coisa” (ALTHUSSER, 1985, p. 97).

Alguém poderia objetar que, nesta última afirmação, Althusser retorna ao primado das práticas ideológicas sobre a categoria de sujeito, mas não esqueçamos a premissa anterior, de que a interpelação ideológica se dá "através do funcionamento da categoria de sujeito".

A despeito do esforço de uma teoria da ideologia "em geral”, “eterna” e “sem história”, como já afirmamos, não é em sociedades

3“Poderíamos claramente objetar que o ‘chamado’ chega individualmente e de maneira implícita e tácita, que a cena nunca é tão didática quanto diz Althusser, mas essas objeções foram ensaiadas, e a ‘interpelação' como doutrina continua sobrevivendo às críticas. Se aceitamos que a cena é exemplar e alegórica, ela não precisa acontecer para presumirmos sua efetividade” (BUTLER, 2017, p. 113-4). 
segmentárias, ditas 'primitivas' ou 'simples', ou em sociedades 'orientais' que Althusser vai pinçar um exemplo para o seu conceito de ideologia. É o cristianismo que funciona para ele como exemplo, e dado que a ideologia é eterna, é "sempre idêntica” em sua "estrutura formal”, tal exemplo seria generalizável para pensar a "ideologia moral, jurídica, política, estética etc.” (ALTHUSSER, 1985, p. 99).

É aqui que Althusser (1985, p. 101-2) insere outro elemento fundamental do seu conceito de ideologia, a saber, a operação “duplamente especular” da ideologia, a ideia de que a interpelação ideológica dos indivíduos concretos como sujeitos implica a existência de um terceiro termo na relação, o Sujeito: "Deus precisa dos homens, o Sujeito precisa dos sujeitos, assim como os homens precisam de Deus, os sujeitos precisam do Sujeito".

Caráter quádruplo do procedimento ideológico (ALTHUSSER, 1985, p. 103): interpela indivíduos como sujeitos; submete-os a um Sujeito; gera reconhecimento mútuo entre os envolvidos; garante que estes "caminhem por si só”, desconhecendo os efeitos que o geraram. Sua temporalidade, diz, está no "sempre-já”, temporalidade que permite a criação de um registro tautológico constitutivo dos agentes do modo de produção e altamente eficaz à sua reprodução.

Se o registro da ideologia ocorre no terreno da eternidade, no sentido de existir enquanto representação da relação imaginária dos indivíduos com as suas condições reais de existência, se somos, sobretudo, animais ideológicos, eis uma hipótese de investigação para as ciências sociais e para a história. Se a ideologia é sempre, eterna e ahistoricamente, constituída pela e constitui a categoria de sujeito/indivíduo, eis uma hipótese menos promissora. Insucesso que o próprio Althusser parece indicar quando elenca a ideologia cristã como exemplo maior do procedimento quádruplo da ideologia e não possíveis formas mais 
remotas, na escala da modernidade, de interpelação, ou quando enfatiza que com o "surgimento da ideologia burguesa, e sobretudo com o da ideologia jurídica, a categoria de sujeito... é a categoria constitutiva de toda ideologia” (ALTHUSSER, 1985, p. 93).

No entanto, o conceito althusseriano de ideologia é particularmente frutífero sem a necessidade de se afirmar como uma teoria da ideologia "em geral” ou predicar a eternidade ou ahistoricidade da interpelação ideológica de indivíduos em sujeitos. Frutífero precisamente ao enfatizar: 1) a materialidade da ideologia, a necessidade de aparelhos que regulem as práticas e rituais de sua produção e reprodução; 2) a produção ideológica de subjetividades como condição necessária para a reprodução de um modo de produção historicamente determinado, deixando aberta a questão de quais são as formas de subjetividade específicas a cada modo de produção; 3) nunca abandonar a intelecção marxiana de que, em última análise, a produção ideológica dominante em uma sociedade se vincula à manutenção e reprodução de variáveis constelações de compromisso entre as classes e frações de classe dominantes (no fundo, vincula-se à luta de classes). ${ }^{4}$

Em que a genealogia foucaultiana da governamentalidade dialoga, avança e/ou retrocede em relação a esse quadro de contribuições e contradições traçado no basilar ensaio Aparelhos Ideológicos de Estado?

\footnotetext{
4"A ideologia dominante nunca é um fato consumado da luta de classes que tivesse escapado à luta de classes” (ALTHUSSER, 1999, p. 239).
} 


\section{Genealogia do Poder: Disciplina, Biopolítica e Governamentalidade}

Semelhante a Althusser, a analítica do poder praticada e sistematizada por Foucault (1988) na sua chamada fase genealógica pretende ir além dos limites postos por uma "hipótese" que concebe o poder como exclusivamente repressivo e que por isso mesmo falsearia, em seu invólucro mórbido e inautêntico, a verdade essencial, escondida e humilhada, dos sujeitos sobre os quais se impõe. Pelo contrário, para Foucault, as subjetividades, e inclusive as resistências, são sempre delineadas e constituídas no interior de relações de poder, e todo poder fundamenta suas práticas em regimes veridicionais. O poder não só reprime, mas também produz, e essa produção, na modernidade do poder, ocorre como produção da verdade.

Assim, uma das principais afinidades entre Althusser e Foucault repousa na destruição do mito dualista que opõe Poder e Sujeito (ver READ 2003, p. 10) e na elaboração de ferramentas conceituais capazes de iluminar a produção de sujeitos por relações de poder ou, nos termos de Althusser, a produção de sujeitos através da interpelação ideológica. A “reordenação conceitual” (PEREZ NAVARRO, 2007, p. 160) realizada por Althusser ao enfatizar, inspirado em Pascal, a primazia das práticas na constituição das ideias e do sujeito ou a materialidade da ideologia, aproxima-o, assim, de aspectos da analítica foucaultiana do poder. Judith Butler é precisamente explícita sobre esse ponto:

A doutrina da interpelação, no pensamento de Althusser, prepara o terreno para as ideias posteriores de Foucault a respeito da 'produção discursiva do sujeito’. Foucault, é claro, insiste que o sujeito não ganha existência por ser 'dito', e que as matrizes de poder e discurso que constituem o sujeito não são singulares nem soberanas em sua 
ação produtiva. No entanto, Althusser e Foucault concordam que existe uma subordinação fundadora no processo de assujettissement (BUTLER, 2017, p. 13-4).

Ambos, Althusser e Foucault, se uniriam como autores fundamentais para um conceito de sujeição, que "significa tanto o processo de se tornar subordinado pelo poder quanto o processo de se tornar um sujeito. Seja pela interpelação, no sentido de Althusser, seja pela produtividade discursiva, no sentido de Foucault, o sujeito é iniciado através de uma submissão primária ao poder” (BUTLER, 2017, p. 10).

Em artigo recente, a mesma afinidade assinalada por Butler é posta em relevo por Julien Pallotta ao tratar do diálogo crítico e implícito do Foucault de 1973 (A Sociedade Punitiva e A Verdade e as Formas Jurídicas) com Althusser. Para Pallotta (2019, p. 24), na leitura daqueles textos de Foucault "frequentemente é a ideia de assujeitamento que é preciso reter”, "retomada manifesta das temáticas althusserianas: a ideia de instituições que assujeitam os indivíduos às exigências da produção capitalista”. ${ }^{5}$

Vimos também como a ideologia, para Althusser, opera através do desconhecimento de que o reconhecimento de si, ao contrário de uma evidência ou verdade indiscutível, é produto da interpelação dos indivíduos concretos em sujeitos. De modo análogo, Foucault (ver FOUCAULT, 2008b, p. 48-50) reflete sobre a unidade da sua obra (ao menos a partir de História da Loucura) em termos de uma investigação, nas mais diversas práticas, da passagem de regimes jurisdicionais de legitimação, por assim dizer, das relações de poder, para regimes de verdade. Para Foucault, portanto, assim como a ideologia

\footnotetext{
5Importa salientar que, aqui, “sujeição”, “subjetivação”, “assujeitamento” são traduções do mesmo conceito de assujettissement. A ideia de que, reiteremos: "Nenhum indivíduo se torna sujeito sem antes se tornar subjetivado ou passar por 'subjetivação’ (tradução do assujettissement francês)” (BUTLER, 2017, p. 19-20).
} 
para Althusser, a eficácia do poder está em se estabelecer como uma evidência. Obviamente, se em Althusser há apenas a enunciação filosófica desse princípio que relaciona ideologia e verdade, Foucault fez das relações entre verdade e poder, conhecimento e dominação, o mote de extensas e aprofundadas pesquisas de orientação históricofilosóficas.

Nesse nível mais geral já são identificáveis, porém, diferenças básicas. Para Althusser, a produção de subjetividades pelos AIE é determinada, em última instância, pela necessidade de produzir as condições de reprodução do modo de produção capitalista. Temos, portanto, um político lido, sobretudo, de uma perspectiva da reprodução, derivada diretamente de uma concepção sobre a determinação econômica em última instância. Foucault, de sua parte, abandona completamente a proposição da determinação econômica em última instância das formações sociais.

Foucault (1979) também rejeita o conceito de ideologia. As razões dadas para tal rejeição indicam, no conceito de ideologia: a referência a um Sujeito, a suposição de uma oposição entre falso e verdadeiro e de uma infraestrutura que a determina.

Sobre este aspecto, Pallotta (2019) assinala de forma precisa, corroborando a nossa leitura na seção anterior, como a crítica de Foucault à noção marxista de ideologia a toma exatamente no estado de definição, residualmente idealista, que Althusser pretendeu superar ao propor uma reelaboração do conceito:

O poder disciplinar se exerce sobre o corpo, e os conduz segundo uma certa norma através de um jogo de recompensas e de punições: ele é incontestavelmente material. Pois, precisamente, e é isso que Foucault não quis ver no artigo de Althusser, em 1970, Althusser propõe um novo conceito de ideologia material segundo a qual as ideias de um sujeito são seus atos materiais inseridos em práticas 
materiais. É assim que podemos nos perguntar se Foucault, em sua rejeição do conceito de ideologia, levou realmente em conta a novidade do conceito althusseriano: de fato o poder disciplinar pensado por Foucault é material assim como é material a ideologia ritualizadas nas práticas reguladas pelos aparelhos ideológicos pensados por Althusser (PALLOTTA, 2019, p. 25).

Isto em um nível mais geral de comparação. Num esforço mais concreto e particularizante, trataremos a seguir das continuidades e descontinuidades de Foucault em relação a Althusser a partir das fases da genealogia pós-soberana do poder, que são basicamente duas: 1) a análise da forma disciplinar ou anátomo-política; 2) a análise da biopolítica e da governamentalidade.

Concordamos com Perez Navarro (2017) e Pallotta (2019) que, mesmo com as diferenças e ruídos notados acima, é na reflexão sobre as formas disciplinares de poder, desenvolvida de forma exaustiva em Vigiar e Punir (FOUCAULT, 1987), que Foucault mais se aproxima da análise dos aparelhos de Estado em Althusser, na medida em que aborda a produção de corpos simultaneamente dóceis e produtivos tanto em instituições com fortes traços repressivos (prisões, quartéis, hospícios) como também na violência sutil do disciplinamento escolar.

A disciplina, como os AIE, realiza-se sobre corpos individuais, interpela os indivíduos através de saberes-práticas (médica, pedagógica, penal, psiquiátrica etc.) que se afirmam como verdadeiros e os transforma em sujeitos (doente, aluno, delinquente, louco etc.).

Embora rejeite completamente a ideia de uma determinação econômica em última instância, Foucault (1988, p. 132) faz questão de salientar, em A Vontade de Saber, como o “biopoder”, e aqui está incluído tanto a anátomo-política como a biopolítica, "foi elemento indispensável ao desenvolvimento do capitalismo, que só pode ser 
garantido à custa da inserção controlada dos corpos no aparelho de produção e por meio de um ajustamento dos fenômenos de população aos processos econômicos”. Complementaridade, portanto, entre a dócil utilidade e produtividade criada pelas tecnologias disciplinares e a regulação controlada dos processos vitais pelas tecnologias biopolíticas.

Coerção e interpelação (Althusser), disciplina e biopolítica (Foucault), são, portanto, fundamentais para a dinâmica econômica capitalista. A diferença no que tange à relação entre poder e economia é que para Foucault, em contraste com Althusser, “o poder não reproduz as relações de produção, ele as constitui”, "não é tanto a reprodução mas a constituição mesma das relações de produção que é preciso pensar" (PALLOTTA, 2019, p. 19).

Outra importante diferença diz respeito ao (não) local do poder. A analítica foucaultiana do poder defende uma abordagem descentralizada, pós-soberana e múltipla das onipresentes relações de poder, onde se diz que "o poder vem de baixo", que "as grandes dominações são efeitos hegemônicos continuamente sustentados pela intensidade” de diversos “afrontamentos” (FOUCAULT, 1988, p. 89-91). Há um interesse explícito na ampliação do instrumental analítico para abordar relações de poder tanto estatais como não-estatais.

Diferente de uma capilarização althusseriana a partir de um centro - o aparelho estatal enquanto produtor das condições repressivas e ideológicas necessárias à reprodução do modo de produção capitalista e sua estrutura de classes — - Foucault privilegia uma análise das formas disciplinares enquanto séries independentes, mas isomorfas, ou seja, equivalentes na forma (apesar da variedade de fins) como se exercem sobre os corpos individuais. Em Althusser, a interpelação dos indivíduos concretos como sujeitos pelos aparelhos ideológicos 
(e repressivos) de Estado; em Foucault o disciplinamento dos sujeitos/corpos individuais por múltiplas práticas de anátomo-política.

Menos explícita do que as afinidades com as tecnologias disciplinares e biopolíticas é a possível interface entre o ensaio sobre os AIE e a elaboração foucaultiana da governamentalidade ou da governamentalização do Estado, presente em Segurança, Território, População (doravante STP) e em Nascimento da Biopolítica (doravante NB).

Se as instituições disciplinares se exercem sobre os corpos individuais (tal como a interpelação ideológica transforma indivíduos concretos em sujeitos), o objeto da governamentalidade é (como na biopolítica) o corpo da população, entendida não só “no sentido tradicional de número de habitantes proporcional ao espaço habitável, mas também como um grupo de indivíduos que possui entre eles relações de coexistência e que constituem, assim, uma realidade específica”, com sua "taxa de crescimento”, “a sua mortalidade e morbidade”, as "suas condições de existência”, “como figura do saber que colabora para a gestão do corpo social” (ANASTACIO, 2017, p. 44).

Em Vigiar e Punir, de 1975, a sociedade disciplinar ou carcerária era pensada como definição essencial das sociedades pós-soberanas e modernas. A partir dos cursos STP e NB, momentos de uma inflexão no pensamento de Foucault, a modernidade do poder, a sociedade de segurança promovida pela governamentalidade, é definida através de um contraste decisivo com a forma disciplinar (SILVA, 2019). Enquanto a sociedade disciplinar é centrípeta, espacialmente restritiva e proibitiva (apesar de já produtiva); a sociedade de segurança definese pelo seu caráter centrífugo, liberalizante e regulamentador, seu objetivo é “fazer de maneira que a realidade se desenvolva e vá, siga seu trabalho, siga seu caminho, de acordo com as leis, os princípios e os mecanismos que são da realidade mesma” (FOUCAULT, 2008a, 


\section{p. 62-3).}

No interior de nossos interesses, reiteremos. O poder disciplinar se aproxima muito mais daquilo que Althusser define em termos de interpelação ideológica, o “Ei, você aí!” que produz o sujeito individual sem o reconhecimento deste, que toma a sua subjetividade como evidência, dado. A análise da governamentalidade, por sua vez, está interessada em uma produção de sujeitos menos pelo modelo do policial, que restringe e enquadra o movimento do indivíduo concreto ao interpelá-lo, do que por uma forma de poder capaz de induzir os próprios indivíduos concretos e a população como um todo a produzir, de forma extensiva e amplificada, a própria subjetividade, sendo essa produção de si mesmo o fulcro da operação do poder.

Nesse sentido, podemos ler a genealogia foucaultiana não só da disciplina (salientada por BUTLER, 2017; PEREZ NAVARRO, 2017; e PALLOTTA, 2019) e da biopolítica (indicada por PALLOTTA, 2019), mas também da governamentalidade, como um desenvolvimento concreto, de forte teor historiográfico, embora abandone o conceito de ideologia, do programa de investigação da produção política de sujeitos definido no ensaio sobre Ideologia e AIE.

Se disciplina e interpelação denotam muito maior familiaridade, a análise da governamentalidade aponta, por sua vez, para um tipo novo, não elaborado por Althusser, de produção política de sujeitos - que, no máximo, estava apenas latente nas formulações sobre a interpelação enquanto fundação de certa subjetividade autônoma.

Em termos da transição histórica das economias de poder, Foucault (2008a; 2008b) está interessado em refletir sobre a passagem de uma arte de governar as coisas e os seres humanos que tem como fim o próprio Estado (razão de Estado) para uma racionalidade (governamentalidade) que institui um princípio de autolimitação do governo: 
o Estado governamentalizado é aquele que não tem mais o fim em si mesmo, mas a regulamentação da população concebida enquanto mercado. A dinâmica espontânea dos interesses no mercado torna-se o critério de limitação da ação estatal.

A governamentalidade é, portanto, uma arte de governar que nasce com o par liberalismo-economia política, racionalidade de governo englobante do próprio aparelho estatal e que enquadra a população como povoada por homo oeconomicus, por sujeitos portadores de interesses tendentes ao bem da população (mão invisível). A governamentalidade liberal clássica produz, interpela, enquadra os indivíduos concretos nos termos de um sujeito que trata

as necessidades individuais e os bens que estão disponíveis ou que devem ser produzidos para a satisfação como números numa contabilidade contínua, e o homem é tratado como um empresário e sua vida como sendo o objeto desta sua empresa administrada nas regras da contabilidade (WEBER, 1995, p. 288).

Foucault (2008a) também escreve em STP que as raízes históricodiscursivas da moderna produção política de sujeitos se encontram no que ele define como poder pastoral. O que oferece ainda mais elementos para reforçar a leitura da genealogia como um desenvolvimento, permeado por (des)continuidades, do programa de investigação delineado por Althusser, já que, como vimos, o autor franco-argelino toma precisamente a ideologia cristã como o exemplo mais frutífero para entender o seu conceito de ideologia em geral.

As fontes discursivas para a análise do pastorado cristão são buscadas em textos principalmente dos séculos III ao VI - São Cipriano, Santo Ambrósio, Gregório (Liber pastoralis), Conferências de Cassiano, São Jerônimo, a Regra de São Bento. Fundamental para o nosso problema é reter a originalidade, salientada por Foucault, do modo de 
individualização desenvolvido pelo poder pastoral como um prelúdio da governamentalidade.

Três são os principais elementos do poder pastoral: identificação analítica, sujeição e subjetivação. É por meio de um processo biográfico, com seus méritos e deméritos, que se constitui um indivíduo, um sujeito que se submete a uma dada ordem de relações (o Sujeito de Althusser) não por meramente internalizar uma verdade imposta, mas por produzir em si mesmo, por meio da confissão (identificação analítica), essa verdade que o leva a entregar-se à comunidade. Por um lado, o "sujeito” é produzido em sua inserção “em redes contínuas de obediência” (FOUCAULT, 2008, p. 243) — sujeição — e é daí que extrai uma verdade para si mesmo. Por outro, esta subjetivação através de um conjunto de relações significa a interposição de fatores mediadores na relação sujeito-verdade; não se trata mais da relação simples do súdito submetido à verdade soberana (ver AVELINO, 2016) ou, para falarmos com Althusser, dos sujeitos em relação ao Sujeito.

A governamentalidade liberal define a liberdade do mercado como limite da ação estatal (demarcando as fronteiras entre o econômico, o político, o jurídico etc. como domínios de racionalidades heterogêneas) e enquadra os sujeitos do mercado como sujeitos da livre troca (o econômico como esfera do laissez-faire). A governamentalidade neoliberal, por sua vez, se caracteriza pela orientação de todas as esferas e racionalidades da sociedade para a constituição da economia de mercado e compreende os sujeitos como capital humano, capazes de pensar todas as instâncias da vida em termos de valorização de si mesmo como uma empresa.

De comum: a afirmação da irredutibilidade da economia de mercado, e dos elementos que a constituem, em relação às instâncias do 
Estado e do direito, irredutibilidade, portanto, do homo oeconomicus ao homo juridicus e ao homo legalis. Comum, também, é a fundação da racionalidade singular do homo oeconomicus na opacidade destes sujeitos em relação à realidade mais ampla que os engloba, e é precisamente por serem cegos à dinâmica própria do mercado que eles, a despeito do que os motiva, realizam a sua natureza ou a sua essência.

É importante reter a seguinte distinção entre o homo oeconomicus liberal e o homo oeconomicus neoliberal:

O liberalismo e a economia política são saberes que constituem práticas de limitação dos diferentes domínios, das racionalidades (econômica, política, jurídica etc.) heterogêneas, para que uma não ultrapasse o limite da outra.

O neoliberalismo, por sua vez, concebe a possibilidade: por um lado, em todas as suas versões, de um compromisso, de uma convergência, entre estas diferentes racionalidades segundo o interesse de constituição da economia de mercado; por outro lado, de forma ainda mais explícita em sua ancoragem norte-americana, de definir todas as outras racionalidades segundo o modelo da empresa. Em outras palavras, há tanto a orientação das racionalidades estatal, jurídica, institucional em geral, em função da constituição da economia de mercado, como a compreensão de outros fenômenos segundo o modelo do homo oeconomicus neoliberal, o capital humano.

Se o parceiro de troca (liberal) e o capital humano (neoliberal) de fato são distintos, ambos não deixam de comungar uma característica fundamental do poder pastoral investigado por Foucault: poder que não somente se impõe como verdade (como Sujeito), ou melhor, como regime de verdade (evidência), mas que também se legitima como se fosse o resultado de uma verdade íntima (dos sujeitos) dos que a ele estão sujeitados. 
Reiteremos: as análises do homo oeconomicus liberal e neoliberal, do parceiro de troca e do capital humano, podem razoavelmente serem lidas como o desenvolvimento de um programa de investigação relativo à produção política do sujeito presente em Althusser. A genealogia da governamentalidade inova: 1) ao analisar a produção política do sujeito para além da dimensão de Estado, ao qual pretende se restringir a análise althusseriana dos aparelhos ideológicos; 2) ao realizar uma ampliação daquele programa de pesquisa através de investigações concretas sobre formas de assujeitamento que - mais do que interpelar, delimitar, enquadrar — induzem o sujeito a expandir continuamente as malhas do poder através da produção de si.

\section{... e volta}

A busca por uma autonomia relativa do político na constituição econômica do modo de produção capitalista direciona Althusser, como se sabe, para o problema do papel do Estado na reprodução social. Ao fazê-lo, a despeito de seus méritos, acaba por minorar, no entanto, a importância das formas ideológicas capitalistas constituídas primariamente a partir do mercado - algo certamente passível de melhor visualização através do Foucault da governamentalidade. Curiosamente, um “não-marxista”.

Sua oposição intransigente frente ao que poderia configurar como um tipo qualquer de “circulacionismo” levará Althusser, inclusive, a simpatizar em alguns momentos com a tradição neoricardiana de leitura do valor como trabalho incorporado (contra a chamada análise da forma-valor ou do trabalho abstrato). ${ }^{6}$ É neste ponto, lançando luz so-

\footnotetext{
${ }^{6}$ Althusser (2006, p. 40) faz referência positiva à concepção neo-ricardiana do valor de Pierro Sraffa, bem como ao fato deste ter logrado evidenciar os erros de Marx em aspectos importantes de sua teoria do valor. Para mais sobre este debate
} 
bre as sombras do esquema de análise althusseriano, onde o Foucault de STP e NB tem mais a oferecer. A governamentalidade neoliberal, aprendemos, se impõe como um redesenho da vida social a partir da lógica concorrencial de mercado: como racionalidade, expande-se do mercado para as demais esferas (mesmo aquelas diretamente relacionadas ao Estado ampliado althusseriano).

Mas o que inicialmente aparece como uma fraqueza da análise althusseriana, pode se apresentar, em outra chave, como força, que ilumina, por sua vez, as limitações foucaultianas para a compreensão do nosso tempo presente. Se é preciso um maior foco nas dinâmicas de mercado, isso não necessariamente significa abrir mão de uma concepção de Estado como importante centro de poder na reprodução capitalista.

Se é correto falarmos, no que se refere à governamentalidade neoliberal, em uma dinâmica difusa e descentrada das relações de poder, pautada pela lógica concorrencial de mercado, que se reproduz sobremaneira a partir daquelas formas de subjetivação que redundam no "governo de si”; é igualmente sabido do caráter socialmente fabricado (POLANYI, 2000) das instituições que reproduzem e recriam de modo continuado o mercado como espaço de centralização-descentralização política. Nessa fabricação continuada, o Estado, como instância material de poder, inclusive de classe, segue, ainda que sob uma apenas aparente diminuição de seu alcance, cumprindo papel absolutamente indispensável: como emissor de moeda; como arrecadador central e gestor estratégico (JESSOP, 2007) de política econômica frente a determinados objetivos e dinâmicas de acumulação de capital; como articulador dos conflitos distributivos; como legislador e aplicador da ordem jurídica, como aparato repressivo e de controle

ver Paraná (2020). 
social etc.

Talvez seja possível dizer, sem risco de exagero, que STP e NB antecipam e anunciam, em certa medida, o advento de uma nova forma capitalista de gestão da vida socioprodutiva, ou, uma reconfiguração das relações entre mercado e Estado, contribuindo para a retificação de uma formulação dos AIE ainda referenciada, em grande medida, no industrialismo welfarista dos países capitalistas centrais, na realidade histórica do regime de acumulação keynesiano-fordista. É razoável, diante disso, como se quer, uma atualização da teoria althusseriana dos aparelhos frente à nova historicidade do capitalismo neoliberal que se consolida nas últimas cinco décadas.

Ocorre que, desde 1979, ano do curso Nascimento da Biopolítica, a consolidação da racionalidade neoliberal como hegemônica torna-se vítima de seus próprios efeitos, caminhando para uma profunda crise (STREECK, 2011). Crise essa que desvela didaticamente, uma vez mais, a importância material estratégica de certos aparelhos ideológicos e repressivos de Estado. E eis que Althusser, ainda que descolado frente ao novo contexto estrutural, é chamado a nos informar a respeito.

Isso porque se trata de uma crise que se expressa, para mobilizar o léxico foucaultiano, no seguinte paradoxo: ao mesmo tempo em que a "racionalidade neoliberal" nunca foi tão dominante, esta enfrenta, seja nos países capitalistas centrais seja nos países periféricos, barreiras materiais cada vez mais expressivas para se afirmar de modo continuado como um "regime de verdade”, “evidência” incontestável ou alternativa única. Deslocando de volta a termos althusserianos: o desencaixe entre a afirmação ideológica do neoliberalismo e as condições materiais para sua reprodução continuada, no quadro de crise do regime de acumulação pós-2008, recolocam, em outro patamar, o pro- 
blema da reprodução social. Automação avançada e reconfiguração estrutural do trabalho, aumento exponencial do desemprego e das desigualdades sociais, políticas e econômicas, crise ambiental, retorno da contestação social, entre tantos outros limites, põem em questão as promessas neoliberais de realização pessoal-individual (FEVRE, 2016) por meio do circuito trabalho-consumo, mesmo para algumas dentre aquelas parcelas sociais desde sempre restritas. Em risco, toda uma forma de conceber e gerir a relação Estado-mercado-sociedade. Em contraste com o triunfalismo das décadas de 1980 e 1990, o mainstream político e econômico neoliberal encontra-se, atualmente, em situação defensiva de incerteza quanto ao futuro.

Há quase cinco décadas, a forma neoliberal de capitalismo comanda as relações econômicas mundiais, rege as políticas públicas, transforma a sociedade, rearticula nossa subjetividade. A globalização e expansão financeira, a conquista do poder político pelas forças neoliberais, o aumento das desigualdades (PIKETTY, 2014) e a polarização crescente entre ricos e pobres, a crescente atomização e individualização das relações sociais, e o consequente desenvolvimento de novas formas de sofrimento psíquico são todas dimensões complementares do processo de neoliberalização — um desenvolvimento articulado, entre outros aspectos, em torno da promoção da concorrência em todas as esferas da vida (DARDOT; LAVAL, 2016).

Eis que a referida crise nos ajuda a entender, então, que o neoliberalismo não é produto tão somente de determinações estruturais rígidas e pré-estabelecidas (o puro desenrolar de uma "lógica do capital” autodeterminada), mas tampouco é um resultado político apenas contingente, eventual, ocasional e não intencional. Configura-se, distintamente, como "sistema normativo", a partir do encontro entre ações e seus desdobramentos particulares, inseridas em um quadro de 
possibilidades delimitado por tendências estruturais mais amplas. É um processo vertebrado, de modo gradual e complexo, e a partir de diferentes esferas, estratos e dinâmicas de (sobre) determinação, que se combinam de modo a produzi-lo como resultado. Mais especificamente, o que ocorre, a partir das décadas de 1970 e 1980, é o encontro particular entre um projeto político de classe (BRUNHOFF, 1991; DUMÉNIL; LEVY, 2004; HARVEY, 2008) com uma dinâmica endógena de regulação - mútua atração entre duas "lógicas” cujo resultado se consubstancia no neoliberalismo. ${ }^{7}$ Ao dizê-lo, já podemos visualizar a intensidade com que as proposições althusserianas lançam luz sobre aquilo que se tornou opaco sob o enfoque foucaultiano.

O traço mais básico do neoliberalismo, de acordo com Saad-Filho e Johnston (2005, p. 3), é o uso sistemático do poder de Estado para impor os imperativos (financeiros) de mercado, num processo doméstico que é replicado internacionalmente por meio da globalização (via imperialismo). A globalização neoliberal, prosseguem Saad-filho e Johntson (2005, p. 4), não configura simplesmente um processo de “desregulação econômica”, e não promove a “iniciativa privada” em geral. Sob uma retórica de não-intervenção, o neoliberalismo mobiliza, em verdade, intervenções extensivas e invasivas em todas as dimensões da vida social. Assim é que, nesse momento, "as condições materiais em que se desenvolve o capitalismo possibilitam que esse ideário mostre-se, sem disfarce, como o discurso nu e cru do capital” (PAULANI, 2005, p. 129).

Para Duménil e Levy (2004), trata-se de um “novo estágio do capitalismo” que surge na esteira da crise estrutural dos anos 1970. "Ele

\footnotetext{
${ }^{7}$ Dardot e Laval (2016, p. 385) estão corretos quando afirmam que, “apesar disso, não houve um projeto consciente de passagem do modelo fordista de regulação para outro modelo que teria primeiro de ser concebido intelectualmente para depois, numa segunda fase, ser posto em prática de forma planejada”.
} 
expressa a estratégia das classes capitalistas em aliança com a alta gestão, especificamente com os executivos financeiros, com a intenção de fortalecer sua hegemonia e expandi-la globalmente" (DUMÉNIL; LEVY, 2004, p. 1). Mas essa ordem neoliberal não se conformou apenas ou centralmente, ainda que de modo complementar a esta, como produto de uma potente virada discursiva:

o neoliberalismo é a expressão do desejo de uma classe de proprietários capitalistas e das instituições em que seu poder está concentrado, o que coletivamente chamamos de "Finança", para restaurar — no contexto de um declínio geral nas lutas populares - seus ganhos e seu poder da classe, que diminuíram desde a Grande Depressão e a Segunda Guerra Mundial. Longe de ser inevitável, essa foi uma ação política (DUMÉNIL; LEVY, 2004, p. 1-2).

Para Brunhoff (1991, p. 14) trata-se, igualmente, de uma "revanche de classe”, diagnóstico compartilhado por Streeck (2018). ${ }^{8} \mathrm{Na}$ mesma direção, tratando da "reação neoliberal” à “utopia keynesiana”, Belluzzo (2016, p. 103) aponta que

a força política das classes proprietárias e dominantes submeteu o Estado e o colocou como executor dos projetos de desregulamentação financeira, como fautor da flexibilização dos mercados de trabalho e garantidor dos movimentos de internacionalização da grande empresa.

Assim é que, conforme Harvey (2008) — e Foucault concordaria, em certa medida —, o neoliberalismo não torna irrelevante o Estado nem instituições particulares do Estado (pensemos, por exemplo, nos tribunais e funções de polícia). O que ocorre, distintamente, é uma

\footnotetext{
8“Aqui contrasto à onda de greves entre 1968 e 1969 uma kaleckiana 'greve de investimentos' nos anos 1970, que reputo ter sido muito mais efetiva que qualquer outra arma que os sindicatos e os ‘dependentes’ de salário já tiveram em seu arsenal” (STREECK, 2018, p. 17).
} 
“radical reconfiguração das instituições e práticas do Estado” (HARVEY, 2008, p. 89). "Por trás dessas grandes mudanças das políticas sociais estão importantes mudanças estruturais na natureza da governança” (HARVEY, 2008, p. 86) - como ilustração, o advento das “parcerias público-privadas”.

O que se busca, portanto, é reforçar, aproximar e integrar o processo de tomada de decisões do Estado à dinâmica da acumulação de capital e às redes de poder de classe. Desse modo (algo que, apenas a uma primeira vista, aparecerá como contraditório com a teoria neoliberal), o braço coercivo do Estado é fortalecido de maneira a proteger interesses corporativos e reprimir o dissenso quando necessário. Tratando do caso estadunidense, Loic Wacquant (2001, p. 96) fala de um imbricamento nada aleatório entre neoliberalismo e Estado punitivista:

Longe de contradizer o projeto neoliberal de desregulamentação e falência do setor público, a irresistível ascensão do Estado penal americano é como se fora o negativo disso - no sentido de avesso mas também de revelador - , na medida em que traduz a implementação de uma política de criminalização da miséria que é complemento indispensável da imposição do trabalho assalariado precário e sub-remunerado como obrigação cívica, assim como o desdobramento dos programas sociais num sentido restritivo e punitivo que lhe é concomitante.

Ora, é precisamente essa dinâmica — de um lado, de produção ideológica, de outro, de rearranjo entre as classes e frações de classe dominantes - que o excesso de autonomia (ou capacidade produtiva) conferida aos discursos ordo e neoliberal deixa escapar em Foucault.

Wendy Brown (2015), autora certamente pertencente ao “campo foucaultiano” de crítica do neoliberalismo, atenta (mesmo que de passagem, e sem retirar disso as devidas consequências teóricas) para 
uma importante debilidade nas formulações do autor: a de que o capital e o capitalismo não podem ser reduzidos apenas à dimensão da razão. Trata-se de apontar a indiferença de Foucault quanto às questões relativas à democracia, de um lado, e ao capital, de outro — duas arestas atribuídas à conhecida oposição do filósofo francês ao marxismo.

Foucault desviou seu olhar do capital em si como uma força histórica e social. Aparecendo com pouca frequência nessas palestras, quando o capital é mencionado, é geralmente para desprezar a ideia de que ele segue uma lógica necessária ou implica em um sistema de dominação. No entanto, capital e capitalismo não são redutíveis a uma ordem de razão (...) Como Max Weber, Karl Polanyi, e não apenas Foucault, nos lembram, o capital exige que certas verdades sejam implementadas, e como a crítica ideológica nos lembra, o capital circula certas verdades para sustentar seu poder, bem como sua legitimidade, ou melhor, para manter sua legitimidade como poder (BROWN, 2015, p. 75).

É precisamente este problema que buscamos contornar ao apontarmos a necessidade da articulação de uma análise do neoliberalismo às tendências e transformações estruturais do processo de acumulação capitalista e ao fortalecimento do poder disciplinar/coercitivo de Estado, assim como recuperar o poder explicativo de uma teoria da ideologia renovada (ver também ZIZEK, 1996, p. 18-9). Afinal de contas, subjetivar o indivíduo como empresa de si e capital humano é, antes de tudo, conformar a realidade social de um tal modo em que o trabalhador veja e produza a si mesmo sob a lente do próprio capital; ou seja, que este se comporte, no interior do processo de exploração e para além dele, em conformidade com aquilo que o é e representa de facto para o capitalista: capital variável (MARX, 2013).

Cabe apontarmos, ademais, que se análises voltadas para o realce das rupturas ou da novidade teórica e sociopolítica materializada no 
neoliberalismo tem seu lugar, sabemos que é possível encontrar também importantes continuidades e semelhanças entre as variantes de liberalismo. Em comum, grosso modo: a aposta no laissez faire, na autorregulação da economia pelo mercado contra toda forma de "intervencionismo”, algo diretamente relacionado ao expediente da privatização/mercantilização crescentes como recurso de fortalecimento do poder de classe, ou seja, de disciplinamento e controle da força de trabalho por meio do desemprego e do ataque às formas de proteção laboral, salário indireto e acesso a bens públicos/comuns.

O neoliberalismo, sabemos também com Foucault, não nega a necessidade de ação estatal. Mas é preciso destacar, em adição, que sua parcial retirada da economia é estratégica do ponto de vista da acumulação. Não se trata, novamente, então, de diminuição do tamanho, importância ou da ação do Estado, mas de uma drástica reconfiguração de seu papel. ${ }^{9}$ E aqui, novamente, junto a Marx, Polanyi, dentre outros, trata-se de corroborar a análise de que o mercado moderno não atua e não pode existir sem o Estado, tendo sido, desde sempre, amparado por este. Para Polanyi (2000), lembremos, a única maneira de se realizar a “utopia” clássica do mercado autorregulável é justamente através do apoio de um forte Estado intervencionista, da violência aberta de classe.

Mas eis que, sob o neoliberalismo, vimos, o Estado passa ele mesmo a ser regulado ao invés de regulador do mercado. De "capitalista ideal generalizado" passa tendencialmente a capitalista particular (atuando abertamente em prol do setor financeiro). De relativamente autônomo frente ao processo de acumulação é levado a submeter-se a certos estratos de classe e frações de capital. ${ }^{10}$ Um Estado que vê,

\footnotetext{
9"A primary ambition of the neoliberal project is to redefine the shape and functions of the state, not to destroy it” (MIROWSKI, 2014, p. 56).

${ }^{10}$ Melhor será dizer da manutenção de sua autonomia, mas agora exercida não
} 
assim, sua soberania ainda mais reduzida ao poder do "mercado" — algo que não ocorre apenas por meio de uma virada política e/ou subjetiva, cabe repetir, mas também como expressão de transformações estruturais do capitalismo.

Indo além, estamos aparentemente, conforme alerta Belluzzo (2013, p. 179), em uma "situação em que a 'grande transformação' ocorre no sentido contrário ao previsto por Polanyi: a economia trata de se libertar dos grilhões da sociedade”; uma liberação que, para retomar a crítica de Brown (2015), atenta contra a própria ideia corrente de democracia, ainda precária, é certo, mas arduamente arrancada em meio às lutas sociais dos últimos dois séculos. Como se disse, o temor de Polanyi era precisamente o de que o projeto utópico do liberalismo — e agora do neoliberalismo, podemos acrescentar — só pudesse ser sustentado pela via autoritária, já que a liberdade das massas teria de ser inevitavelmente restringida em favor da liberdade de alguns poucos.

A redução das "liberdades" à "liberdade de empreendimento" desencadeia todas as "liberdades negativas" que Polanyi considerou inextricavelmente ligadas às liberdades positivas. A reação inevitável é reconstruir solidariedades sociais, embora seguindo linhas distintas - o que explica o renascimento do interesse pela religião, pela moralidade, por novas formas de associacionismo (em torno de questão de direitos e cidadania, por exemplo) e mesmo o retorno de antigas formas políticas (fascismo, nacionalismo, localismo e coisas do tipo). O neoliberalismo em sua forma pura tem sempre ameaçado conjurar sua própria nêmesis em variedades autoritárias de populismo e nacionalismo (HARVEY, 2008, p. 91).

em favor de ganhos eventuais para os trabalhadores, maiorias sociais e minorias políticas, ou em favor da ativação de uma estratégia desenvolvimentista em aliança com setores produtivos, mas em prol de uma restrita elite de capitalistas financeiros (pensemos aqui no papel do sistema jurídico, do Banco Central e outras instituições em seu engajamento direto no processo de financeirização generalizada das economias). 
Mas eis que, para voltarmos àquele ponto de inflexão da análise, para espanto de muitos, a grande crise de 2008 não levou ao desaparecimento, sequer ao enfraquecimento do neoliberalismo e das políticas neoliberais. Ao contrário, em meio aos ilusionismos típicos da “doutrina de choque” (KLEIN, 2007), a crise apareceu para as classes dirigentes como uma oportunidade bem-vinda, conduzindo, assim, ao seu fortalecimento. Pensemos aqui nas repetidas rodadas de austeridade (BLYTH, 2017) impostas aos Estados ademais diretamente engajados eles mesmos no aprofundamento da lógica da concorrência nos mercados financeiros. Desse modo, as crises não parecem ser, para o neoliberalismo, uma ocasião para sua limitação, como vimos ocorrer no pós-guerra, "mas um meio de prosseguir cada vez com mais vigor sua trajetória de ilimitação. O capitalismo, com ele, não parece mais capaz de encontrar compensações, contrapartidas, compromissos” (DARDOT; LAVAL, 2016, p. 8). Eis que podemos, por fim, voltar então àquele paradoxo: o desencaixe entre a força ideológica do neoliberalismo e as condições materiais para sua reprodução continuada como modo de regulação capitalista.

Assim sendo - considerando o caráter crescentemente disciplinar de gestão dos conflitos sociais sob a ordem neoliberal, a forma autoritária de repressão do dissenso político e o esvaziamento das concessões e mecanismos decisórios da velha democracia representativa liberal - , talvez seja possível, e ademais necessário, nos perguntarmos sobre a existência e, se assim o for, sobre o estatuto dos novos aparelhos de Estado. Aparelhos esses que, nesta conjuntura de crise do neoliberalismo, ou de uma governamentalidade neoliberal "tardia”, caso se queria, aparecem finalmente como aparelhos repressivos/ideológicos de Estado-mercado ou de mercado-Estado - e cujo o caráter de classe, a ver a elevação brutal da desigualdade econômica, 
não é possível ignorar.

\section{Conclusão}

Esse conjunto de considerações nos permite retornar, sinteticamente, à problemática do assujeitamento ou da sujeição — que, como vimos, estabelece um claro vínculo entre as obras de Althusser e Foucault no sentido de um diagnóstico do presente:

1) Primeiramente, o paradoxo de uma dominância global, radicalizada pela financeirização, simultânea à crise incontestável do neoliberalismo, evidencia que a tríade formada por coerção/interpelação/disciplinamento, mais amplamente abordada por aquelas/es que comentam as relações entre Althusser e Foucault, não pode, de modo algum, ser considerada um anacronismo ou elemento secundário, como queria o Foucault da governamentalidade, nos processos e atos de sujeição contemporâneos.

Frente a um sistema mundializado incapaz de refundar-se enquanto regime de verdade ou como racionalidade de governo legítima, e que expande-se e aprofunda-se como produtor de desintegração sociossistêmica permanente (STREECK, 2017), o uso da coerção do Estado e para além dele - e da interpelação - ideológica e disciplinar, estatal ou não-estatal — realiza-se contínua e cotidianamente:

a) por meio do Estado penal, orientado para a gestão punitivista e racista do desemprego e da pauperização; b) como forma de reorientar indivíduos, grupos e classes aos marcos de um Estado de Direito instrumentalizado por governos autoritários e autocráticos; c) por grupos e partidos políticos que buscam dar sentido e mobilizar segmentos da população (atingidos em graus variáveis e de formas distintas pela ratio neoliberal) através de políticas de identidade que estabelecem, por 
meio de violência física e simbólica, fronteiras rígidas entre o eu e o outro, entre o que deve viver e o que deve morrer.

Em tais formas de sujeição, a produção dos sujeitos, num jogo de reconhecimento/desconhecimento, a partir de um Sujeito - Estado, Pátria, Nação, Líder — revela particular atualidade.

2) Em segundo lugar, não se pode negar a perenidade de discursos como o capital humano e o empresário de si, salientados por Foucault para caracterizar a racionalidade de governo neoliberal, na compreensão do capitalismo contemporâneo. Enraizada numa crítica ao fascismo, ao socialismo e ao keynesianismo, tal governamentalidade tendeu a identificar todo intervencionismo estatal como germe potencial de totalitarismo. Assim, buscou e busca articular-se como regime de verdade que defende, de forma intransigente, a autonomia e liberdade individuais contra toda tirania. Nesse sentido, puramente discursivo, a análise de Foucault do ordo e do neoliberalismo - como defesa da diferença e da autoprodução/autovalorização de sujeitos entendidos como empresários de si, contra toda reificação e estatização da vida, contra todo Sujeito e sua unidimensionalidade - lança luz sobre um aspecto decisivo dos meandros prático-discursivos a partir dos quais o neoliberalismo se expandiu e impôs-se como nova razão do mundo.

No entanto, como vimos, do discurso à prática, do conceito à história, a governamentalidade neoliberal não se efetivou, ou melhor, não enformou a sociedade global apenas através da multiplicação de instâncias jurídicas de apelação contra quem colidisse com as normas da economia de mercado. O intervencionismo estatal manteve-se e permaneceu como instrumento constante, num sentido oposto ao pacto fordista-keynesiano ou ao planejamento socialista, agindo em favor do duplo processo: de primazia financeira das dinâmicas de valorização do valor e de desregulamentação, flexibilização e precarização 
das relações e organizações do trabalho.

A racionalidade de governo neoliberal, articulada ao desenvolvimento exponencial das TICs, de fato foi veículo fundamental para a mundialização dos processos produtivos e financeiros, concretizando, em parte, aquilo que Foucault percebeu (em contraste com uma sociedade disciplinar centrípeta) como o seu caráter centrífugo, de expansão e interconexão crescente dos processos e dinâmicas populacionais. No entanto, do ponto de vista das sujeições ou subjetivações, quase 50 anos de neoliberalismo, se contarmos a partir de Pinochet, revelam o caráter fundamentalmente restritivo daqueles sujeitos que gozam do atributo da mobilidade quase ilimitada e de um posicionamento na estrutura de oportunidades do mercado que os permita existir e se expandir como empresários de si.

Na sombra do homo oeconomicus definido como capital humano, a governamentalidade neoliberal foi e é uma produtora em massa de sujeitos de sacrifício (BROWN, 2015) que, voluntária ou coercitivamente, são gradual ou paulatinamente eliminados em nome de metas fiscais, austeridade e solvência financeira.

Também o retraimento radical dos mecanismos de providência e salário indireto criam condições sociais de extrema competição entre indivíduos, ${ }^{11}$ famílias e agrupamentos sociais diversos, generalizando um quadro social de desintegração e anomia onde a dupla contingência que permeia a relação ego/alter tende a ser "solucionada” numa representação do outro como ameaça latente ou através da sua elimi-

\footnotetext{
${ }^{11}$ Trata-se da produção deliberada de uma "insegurança” que possibilita um tipo de configuração do mercado de trabalho mais favorável ao capital. Muitas análises apontam o desemprego como um efeito colateral das medidas neoliberais de austeridade. Ocorre que, de certo modo, para os neoliberais, o desemprego é o próprio objetivo. O desemprego desorganiza os trabalhadores, rebaixa salários e leva potencialmente a uma recuperação da “disciplina”, nos termos de Kalecki (1943), no ambiente de trabalho.
} 
nação. Neste sujeito, são potencializadas as tendências antipáticas do blasé simmeliano e autoritárias da personalidade produzida pelo capitalismo tardio.

3) Por fim, como vimos, Foucault critica e rejeita um conceito de ideologia numa acepção, podemos dizer, pré-althusseriana. Como apontado por Pallotta (2019), se tivesse dialogado diretamente com a redefinição da ideologia por Althusser, várias afinidades seriam perceptíveis - ambos rejeitam uma concepção substancialista e enfatizam a dimensão relacional, produtiva, material e prática da ideologia (Althusser) e das relações de poder (Foucault). Numa dedução lógica algo duvidosa, para Foucault, rejeitar uma concepção substancialista do poder é também negar qualquer noção de grupo ou classe dominante que, supostamente, deteria o poder. Não se considera que, mesmo no "modelo belicista” (PALLOTTA, 2019, p. 28) das relações de poder, é possível pensar em uma distribuição desigual e dinâmica dos dispositivos e práticas que são a existência mesma daquelas relações.

É o próprio neoliberalismo histórico que faz saltar aos olhos a crescente concentração de recursos — materiais e disposicionais, alocativos e autoritativos - econômicos, políticos e culturais em frações de classe exíguas pari passu a processos globais de pauperização. É também o próprio neoliberalismo histórico que exige repensar se, de fato, as relações de poder e as racionalidades de governo se constituem e desenvolvem-se, como pensava Foucault, desvinculadas do que Althusser chamou de ponto de vista da reprodução do modo de produção capitalista. Reprodução esta que, dando razão a Foucault desta vez, mobiliza processos de sujeição que incluem, mas também vão bem além dos aparelhos repressivos e ideológicos de Estado. 


\section{Referências}

ALTHUSSER, Louis. Aparelhos Ideológicos de Estado. Rio de Janeiro: Graal, 1985.

. Philosophy of the Encounter. Later Writings 1978-86. London: Verso, 2006.

. Por Marx. Campinas: Editora da Unicamp, 2015.

. Sobre a reprodução. Petrópolis: Vozes, 1999.

ANASTACIO, Lara Pimentel Figueira. Governo das condutas: técnica e reflexão em Foucault. Dissertação de mestrado. Departamento de Filosofia, Universidade de São Paulo, São Paulo, 2017.

AVELINO, Nildo. Foucault e a racionalidade (neo)liberal. Revista Brasileira de Ciência Política, $n^{\circ}$ 21. Brasília, setembro-dezembro, p. 227-284, 2016.

BALIBAR, Étienne. Althusser and the 'Ideological State Apparatuses'. In: . On the reproduction of capitalism: ideology and ideological state apparatuses. London, New York: Verso, 2014.

BELLUZO, Luiz Gonzaga de Mello. O capital e suas metamorfoses. São Paulo: Editora Unesp, 2013.

BIDET, Jacques. An Invitation to Reread Althusser. In: On the reproduction of capitalism: ideology and ideological state apparatuses. London, New York: Verso, 2014.

. Foucault with Marx. London: Zed Books, 2016.

BLYTH, Mark. Austeridade: a história de uma ideia perigosa. São Paulo: Autonomia Literária, 2017.

BROWN, Wendy. Undoing the Demos: Neoliberalism's Stealth Revolution. New York: Zone Books, 2015.

BRUNHOFF, Suzanne de. A hora do mercado: crítica do liberalismo. São Paulo: Editora Unesp, 1991.

BUTLER, Judith. A vida psíquica do poder: teorias da sujeição. Belo Horizonte: Autêntica Editora, 2017.

DARDOT, Pierre; LAVAL, Christian. A Nova Razão do Mundo. São Paulo: 
Boitempo, 2016.

DUMÉNIL; Gerard; LÉVY, Dominique. Capital Resurgent: Roots of the Neoliberal Revolution. Cambridge, MA, London: Harvard University Press, 2004.

FEVRE, Ralph. Individualism and Inequality: The Future of Work and Politics. Cheltenham, Northampton: Edward Elgar, 2016.

FOUCAULT, Michel. Verdade e Poder. In: Microfísica do poder. Rio de Janeiro: Edições Graal, 1979.

. Vigiar e Punir. Petrópolis: Vozes, 1987.

. História da sexualidade (v. 1 A vontade de saber). Rio de Janeiro: Edições Graal, 1988.

. Em Defesa da Sociedade. São Paulo: Martins Fontes, 1999.

. Segurança, território, população: curso dado no Collège de France (1977-1978). São Paulo: Martins Fontes, 2008a.

. Nascimento da biopolítica. São Paulo: Martins Fontes, 2008b.

HARVEY, David. O neoliberalismo: história e implicações. São Paulo: Edições Loyola, 2008.

JESSOP, Bob. Estratégias de acumulação, formas estatais e projetos hegemônicos. Revista Ideias, ano 14, (1/2), 2007.

KALECKI, Michal. Political Aspects of Full Employment. Political Quarterly, 14/4, p. 322-331, 1943. Disponível em: delong.typepad.com. Acesso em: 23 jun. 2020.

KLEIN, Naomi. The shock doutrine: The rise of disaster capitalism. New York: Metropolitan Books, 2007.

MARX, Karl. Grundrisse: manuscritos econômicos de 1857-1858: esboços da crítica da economia política. São Paulo: Boitempo; Rio de Janeiro: Ed. UFRJ, 2011.

. O Capital, v. I. São Paulo: Boitempo, 2013.

MIROWSKI, Philip. Never Let a Serious Crisis Go to Waste: How Neoliberalism Survived the Financial Meltdown. New York: Verso Books, 2014.

NEGRI, Antonio. Marx and Foucault, v. I. Cambridge, UK; Malden, MA, 
Polity Press, 2017.

PARANÁ, Edemilson. Bitcoin: a utopia tecnocrática do dinheiro apolítico. São Paulo: Autonomia Literária, 2020.

PALLOTTA, Julien. O efeito-Althusser sobre Foucault: da Sociedade Punitiva à Teoria da Reprodução. Revista de Filosofia Moderna e Contemporânea, v. 7, n. 1, p. 15-29, abril 2019.

PAULANI, Leda. Modernidade e discurso econômico. São Paulo: Boitempo, 2005.

PEREZ NAVARRO, Pablo Francisco. Dos extraños compañeros de cama. La ideología y el poder en Althusser y Foucault. Tabula Rasa, Bogotá, n. 7, p. 149-178, dez. 2007.

PIKETTY, Thomas. Capital in the Twenty First Century. Harvard, MA: Harvard University Press, 2014.

POLANYI, Karl. A grande transformação: as origens de nossa época. Rio de Janeiro: Campus, 2000.

READ, Jason. The Micro-Politics of Capital: Marx and the Prehistory of the Present. New York: State University of New York, 2003.

RYDER, A. Foucault and Althusser: Epistemological Differences with Political Effects. Foucault Studies, n. 16, p. 134-153, Set. 2013.

SAAD-FILHO, Alfredo; JOHNTSON, Deborah. Introduction. In: Neoliberalism: A Critical Reader. London: Pluto Press, 2005.

SILVA, Lucas Trindade da. Inflexão na abordagem genealógica da modernidade em Michel Foucault: do arcaísmo disciplinar à sociedade de segurança. Revista Brasileira de Ciência Política, n. 30, p. 275-314, 2019.

STREECK, Wolfgang. The crises of democratic capitalism. New Left Review, n. 71, p. 5-29, Sept/Oct. 2011.

. Como terminará el capitalismo? Ensayos sobre un sistema en decadencia. Madrid: Traficantes de Sueños, 2017.

. Tempo comprado: a crise adiada do capitalismo democrático. São Paulo: Boitempo, 2018.

WACQUANT, Loic. As prisões da miséria. Rio de Janeiro: Jorge Zahar, 2001. 
WEBER, Max. Teoria sobre o limite do aproveitamento e 'a lei fundamental psicofísica'. In. Metodologia das ciências sociais (parte II). São Paulo: Cortez, 1995.

ZIZEK, Slavoj. Introdução. In: . (Org). Um mapa da ideologia. Rio de Janeiro: Contraponto, 1996. 


\section{Resumo:}

Em busca de uma leitura teoricamente informada das transformações recentes no processo de subjetivação neoliberal, este artigo se desenrola a partir da seguinte questão: em que medida a genealogia da governamentalidade de Michel Foucault dialoga, avança e/ou retrocede em relação ao quadro de contribuições e contradições traçado pela obra de Louis Althusser? A investigação é guiada pela hipótese de que é possível ler a genealogia foucaultiana, tanto da disciplina como da governamentalidade, como um desenvolvimento concreto do programa de investigação da produção política de sujeitos definido no basilar ensaio de Althusser. Trata-se, portanto, de mapear o modo como Althusser informa Foucault para, na volta, refletir em que nível tais formulações foucaultianas podem contribuir à (re)leitura de Althusser e, assim, para uma crítica a ambos em prol de um arcabouço de análise melhor adequado à presente conjuntura do capitalismo.

Palavras-chave: Neoliberalismo; ideologia; governamentalidade; Foucault; Althusser. 


\begin{abstract}
:
Neoliberalism; ideology; governmentality; Foucault; Althusser.

Keywords: In search of a theoretically informed reading of the recent transformations in the neoliberal subjectivation process, this article is based on the following question: to what extent does the Michel Foucault's genealogy of governmentality dialogue, advance, and/or regress in relation to the framework of contributions and contradictions outlined in Louis Althusser's work? The analysis is guided by the hypothesis that it is possible to read the Foucaultian genealogy of both discipline and governmentality as a concrete development of the research program of the political production of subjects defined in Althusser's seminal essay. It is, therefore, a question of mapping the way in which Althusser informs Foucault to think of at what level such Foucaultian formulations can contribute to the (re)reading of Althusser and thus to a critique of both in favor of a framework of analysis better suited to the present conjuncture of capitalism.
\end{abstract}

